\title{
The Design and Reform of Bioengineering Course and Optimization of Resources
}

\author{
Rui Sun \\ School of Food Science and Engineering, Qilu University of Technology, Jinan, Shandong, China. \\ sr@qlu.edu.cn
}

Keywords: Biological engineering, Teaching resources, Integration, Optimization.

\begin{abstract}
How to integrate and optimize the teaching resources is not only a main task of biological engineering teaching, but also an important issue required careful thought and inquiry. This thesis makes a comprehensive discussion of biological engineering teaching resources' integration and optimization.
\end{abstract}

\section{Introduction}

The biotechnology industry, as a dominant promising industry, has already become a strategic focus and a new economic growth point of industrial restructuring, which has the potential to promote and catch up with the productivity levels of developed countries. And then to achieve the advantage and leapfrog development. Fermentation engineering, cell engineering, enzyme engineering, biological separation engineering and biomedical engineering are the main technical systems in the field of biotechnology and engineering. And the biological purification and medical substances extraction are in high demand in this field. Therefore, the construction of bio-engineering curriculum, teaching model to carry out exploration and practice-related courses have a very important practical significance on biotechnology training of personnel [1,2].

\section{The Growth and Enhancement of the Faculty}

Teachers who engaged in teaching and research work are the core resources of university. So teachers should have the abilities of both theory teaching and practical teaching, especially in fermentation engineering, cell engineering, enzyme engineering, biological separation engineering and biomedical engineering. Meanwhile, it's vital for teachers to involve actively in some significant R\&D work in companies; they can gain extensive practical experience which is beneficial to cultivate students' ability to research and practice.

\section{Enrichment and Update of the Teaching Content and Curriculum System}

Fermentation engineering, cell engineering courses are professional platform, and enzyme engineering, biological engineering and biomedical engineering separation are elective subjects, which have a vital importance for students to acquire biological engineering knowledge. At the same time, curriculum should try to reflect systematic, basic, scientific, practical and frontier. Firstly, based on the developments of home and abroad, the content of teaching should be congruent with the current situation, and update it constantly to form a successive system. Secondly, the teaching content materials should be combined with other reference books to enrich the extension. By viewing domestic and foreign professional magazines and online journals, screening professional website, we need to integrate thematic learning resources, and strive to blend multidisciplinary thematic content, timely manner to reflect dynamic frontier in related fields, to make teaching a more substantial novel $[3,4]$. By learning thematic resources, we can promote students' knowledge of construction and self-development (refer with: Fig 1.).

Fermentation engineering project aims to enable students to understand the problems and biological phenomena fermentation process, by familiar with process of fermentation processes and providing students with an initial understanding of the characteristics and commonalities of the 
fermentation industry control. At the same time, it help to grasp the basic concepts of process optimization and enlarge the fermentation process by virtue of cell engineering lectures whose key technologies and applications is the main line, focusing on timely updates to reflect today's latest developments lectures in biotechnology. Students can know about the achievements in enzyme engineering by introducing basics of enzyme engineering systematically, especially some new theories and latest progress. Bio-separation engineering strives to make students master the basic knowledge of basic principles, methods and equipment related to the typical unit operations in the biological separation process and understand the basic engineering theory so that get the ability to produce actual problem analysis, which can lay the foundation for future engineering research and development in biotechnology products. Biomedical engineering is to explain the body's structure, function and relationship from the engineering point of view, reveals its biological phenomena and provides some new technical tools for disease prevention and treatment.

According to course requirements, various courses need crafting Teaching. For example, in "Enzyme Engineering" courseware, teachers can provide a lot of extra-curricular knowledge links for students to expand students' understanding of a wide range of industry sectors."Fermentation Engineering" follows the principle of progressive approach to teaching, focusing on the combination of the various chapters, the emphasis on the concept, emphasizing applications. By introducing the scientific literature to explain, teachers may not only help students grasp the theoretical knowledge, but also provide some scientific analysis. For example, in the teaching how to improve the expression of the cell. Introduced by the representative literature, students may design promoter, and consider other expression elements, select the appropriate cell lines, cell lines with high expression of aspects of media optimization, optimization of culture conditions, such as a comprehensive learning and strengthen the theoretical knowledge systematic and rational. Teachers can write lectures which adapt to "Biomedical Engineering", and introduce a large number of frontier development results in Introduction Science, Nature and other top international journals. From the particularity of the curriculum areas, teachers may vigorously reform the teaching content; create real-time interpretation of the literature and other teaching methods. Teachers need to train students independent study ability, which may reflects evaluating the effectiveness of the paper as a new mode of curriculum assessment, to stimulate students' interest in learning interdisciplinary knowledge, and to train students ask questions, analyze problems and problem-solving skills[5,6].

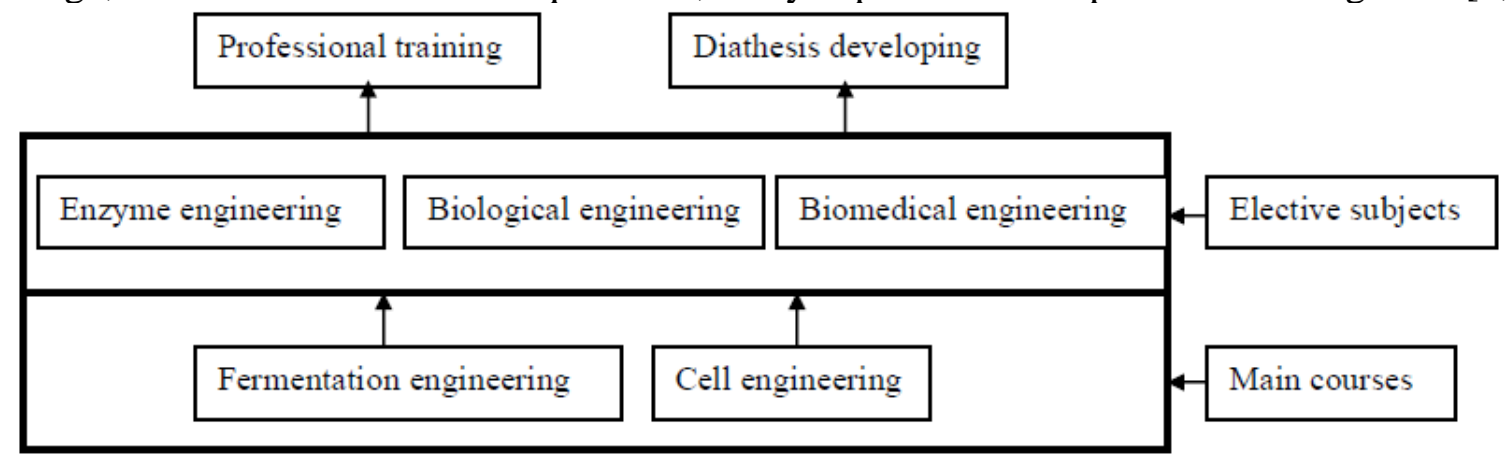

Fig.1 Enrich teaching content and curriculum system

\section{Application of Advanced Teaching Methods and Means}

The purpose of modern education is not simply to impart knowledge, but rather should focus on the capacity and quality of training, especially foster innovation, which is key to develop high-quality talent, which is required to develop students' scientific research ability. Another important aim of modern education is to help students learn independent learning, Lifelong learning methods, which is a requirement of the knowledge economy [7, 8]. To meet this requirement, we employ a large number of heuristic, interactive, case-based teaching and research on teaching methods and means, thus to better promote the active participation of learners, but it also has put forward higher requirements for teachers (refer with: Table 1.): 
1) Focus on the combination between imparting knowledge and capacity development in teaching. Courses are using multimedia teaching methods, I making Multimedia courseware which is content-rich, and timely to update and enrich the teaching content and strive to make the image more intuitive, easy to understand and enrich the novel.

2) Network teaching has the following characteristics: large amount of information, basic concepts and principles of the available material can be illustrated by the different media, selecting a teaching materials and teaching resources should be conducive to the manufacture of a complete knowledge system, conducive to learners to utilize the knowledge gained, conducive to improving the learner to get a good mental training and thinking ability. We can build online courses, upload syllabus, PPT courseware, exercises, reference materials, self-test questions, etc., which are open to students and provide more learning resources for students through a network of teaching methods to meet the needs of independent learning.

3) Using interactive heuristic, interactive, case-based and seminar-style teaching methods, paying attention to interaction teaching and learning, which is not only conducive to active classroom atmosphere, but also help to increase interest in learning, deepen understanding of theoretical knowledge, and stimulate students' learning potential. After-school tutoring distributed to students through the mail, answering through the QQ group, text messaging and e-mail, etc., helping students to further learning, understanding and consolidate and improve learning efficiency. For example, in "Enzyme Engineering" teaching process, we can combine the course content with research focus areas of expertise. Thus form a number of discussion topics. Student can select a topic, form a group and make PPT presentation making PPT presentations. And the winners will be awarded.

4) In the teaching course of "Cell Engineering", when talking about the classification of animal cell fermentation tanks, we can teach the advantages and disadvantages of various designs. This will not only give students about existing fermentation, also ask students to design their own ideal animal cell fermentation tanks, which can give full play to the initiative of students. Although there are many flaws in the design of the students, but mostly is very creative, Design thinking is bold and innovative, which fully embodies innovation."Bio-separation engineering" course can change the traditional modes of teaching; the teacher tries to layout issues using autonomous learning through student lectures. In order to understand the biological product of a separation process, students need a refresher to learned separation method. Moreover, mutual review between the students also encourages everyone to discover each other's strengths and weaknesses. The students learn to think about problem in teacher's perspective, which effectively increases the motivation to learn, but also to enable students to be more respect for teachers teaching achievements. In the "Biomedical Engineering" course teaching, through real-time on the latest literature, we show students the forefront of the latest academic development. Introduction era scientific figures, not only enable students a broad understanding of the development trend of disciplines, but also stimulate their desire for scientific literacy and their own scientific practice.

Tab.1 Application of advanced teaching methods and means

\begin{tabular}{ccc}
\hline Item & Directions & Contents \\
\hline Teaching methods and means & $\begin{array}{c}\text { Capacity and quality of } \\
\text { training }\end{array}$ & $\begin{array}{c}\text { The combination between } \\
\text { imparting knowledge and } \\
\text { capacity development } \\
\text { Network teaching }\end{array}$ \\
& Modern education & Interactive teaching methods \\
\hline
\end{tabular}

\section{The Strengthening of the Experiment and Practice Teaching}

Experiment and practice teaching plays an important role in the quality of education in colleges and universities. It is not only to impart knowledge, to verify theories, develop skills, but also to cultivate students ' scientific way of thinking, to improve students' ability to analyze problems and 
solve problems, to develop good scientific literacy and the spirit of exploring truth, which is important for training comprehensive high quality compound talents. Course Construction of bio-engineering experiments should be a particular focus, practice teaching, which aims to improve students' basic ability to observe and practice to master the basic professional skills test. According to the actual situation and personnel training school goals, relying school research resources, in the same time focusing on laboratory studies, experiments and practical teaching need special attention to operational practice basic skills $[9,10]$. Bio-engineering courses are focusing on applications. Classroom teachers are focusing on the theory and practice in the teaching process. In addition, classroom teachers also try to arrange professional training for students in the college internship base and business in order to improve students' practical skills.

\section{References}

[1] R.N. Coger, H.V. De Silva, An integrated approach to teaching biotechnology and bioengineering to an interdisciplinary audience, International Journal of Engineering Education. 15 (1999) 256-264.

[2] T. Tang, Reform and Research on Experimental Course of Biochemistry of Bioengineering Specialty, Experiment Science and Technology. 1 (2012) 108-109.

[3] R. Perez-Castillejos, W.C. Hunter, B. Mantilla, D. Ivanov, BioMEMS Summer Bioengineering Institute: Integrating engineering and biology education through BioMEMS design, fabrication, and test, IEEE, 2012, 1-4.

[4] X. Xiao, Cultivation of the Engineering Quality of Bioengineering Specialty Students in Local Universities [J], Journal of Anhui Agricultural Sciences. 14 (2012) 8397-8398.

[5] W. Liang, Z. Zhihong, W. Wenhua, T. Ran, Development of an Intelligent Management System for Laboratories, Research and Exploration in Laboratory .5 (2012) 169-172.

[6] Y.H. Sun, M. You, H.Z. Yu, C.H. Huang, Discussion on High-Quality Curriculum Construction of Welded Structure in Local Comprehensive Universities, Advanced Materials Research. 785 (2013) 1502-1505.

[7] R.S. Toledo, I.A. Pérez, D.Z. Pareja, Contribution of the Physics to Development of Research Skills in Biomedical Engineering Students, Springer, 2015, 999-1003.

[8] M. Roman, D. Popescu, D. Selisteanu, An Interactive Teaching System for Bond Graph Modeling and Simulation in Bioengineering, Educational Technology \& Society. 16 (2013) 17-31.

[9] H. Lin, H. Zhi-gang, F. Zhi-peng, on teaching reform of the Biomedical Engineering experiment courses, Journal of Nanchang College of Education. 3 (2013) 52-53.

[10] L.C. De Campos, E.A.T. Dirani, A.L. Manrique, Project Approaches to Learning in Engineering Education: The Practice of Teamwork: The Practice of Teamwork, Springer Science \& Business Media, 2012. 